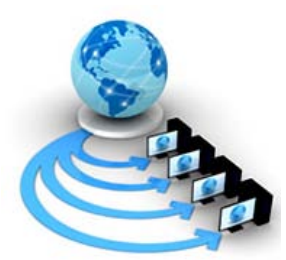

Volume 8, No. 9, November-December 2017

International Journal of Advanced Research in Computer Science

RESEARCH PAPER

Available Online at www.ijarcs.info

\title{
MECHANICAL AND MICROSTRUCTURAL CHARACTERIZATION OF FRICTION STIR WELDED AA 6061 \& AA 2024 DISSIMILAR ALUMINUM ALLOY JOINTS
}

\author{
Koona Shiva Prasad \\ P.G Scholar, Department of Mechanical Engineering, S R \\ Engineering College, Warangal, Telangana state, India
}

\author{
Aruri Devaraju \& Kamarapu Santhosh Kumar \\ Assistant Professor, Department of Mechanical Engineering, S \\ R Engineering College, Warangal, Telangana, India
}

\begin{abstract}
The effect of tool rotational speed on tensile properties and microhardness of dissimilar Aluminum alloys $6061 \& 2024$ welds fabricated via friction stir welding (FSW) have been analyzed in this current study. The different weldments are fabricated by diverge the rotational speeds of the tool as 900, 1120 and $1400 \mathrm{rpm}$. In all the experiments the rotating speed is fixed at $40 \mathrm{~mm} / \mathrm{min}$. For both the alloys all the weld produced should be perpendicular to the rolling direction. Microhardness (Hv) and tensile tests are performed at room temperature to evaluate the mechanical properties of the weldments. It is seen that better tensile properties are exhibited at $900 \mathrm{rpm}$ instead of 1120 and 1400 rpm. It is also observed that at 1120 rpm micro hardness is $115 \mathrm{Hv}$ obtained. The observed tensile properties and hardness are correlated with microstructure and fracture features.
\end{abstract}

Keywords: Friction Stir Welding; 6061 \& 2024 Aluminum Alloy; Microstructure; Tensile Properties; Fractography

\section{INTRODUCTION}

6061 and 2024 Aluminium alloys are extensively utilizing in several emerging fields of aerospace and marine industries in the construction of frames, pipelines and storage tanks. The dissimilar welding process is considered as an exigent one when compared to similar welding process, due to variation in chemical composition, thermal and mechanical properties of the base materials [1-3]. In fusion welding of dissimilar Aluminum alloys is monotonous, FSW process is widely used for welding of dissimilar materials, where the formation of secondary phase is absent since the temperature engaged with this procedure is well beneath the softening temperature of base materials. Prior research were demonstrated that the ideal parameters for welding of unique aluminum combinations, with revolution speed of 600-1000 Rpm, cross speed around $15-40 \mathrm{~mm} / \mathrm{min}$ and $\mathrm{D} / \mathrm{d}$ proportion of 3:1[4]. Apparatus stick profiles, for example, strung, squared and triangular are proficient to exchange the material through and through of the joint and the other way around by blending activity. Aruri was said apparatus rotational speed assumes an indispensable part in FSW and preparing of Aluminum compounds [6]. Many of researchers were mainly addressed the microstructure and mechanical properties of tool geometry and its influences on base material. A narrow literature has focused on the process parameters of FSW. The shape of the tool pin influences the flow of plasticized material and affects weld properties [7-8]. The aim of this work is to analyze the effect of tool rotational speed on tensile properties and microhardness of dissimilar Aluminum alloy 6061 \& 2024 welds fabricated via friction stir welding (FSW).

\section{MATERIALS \& EXPERIMENTAL PROCEDURES}

a. Materials:

Aluminum alloy $6061 \& 202$ b. Methodology:

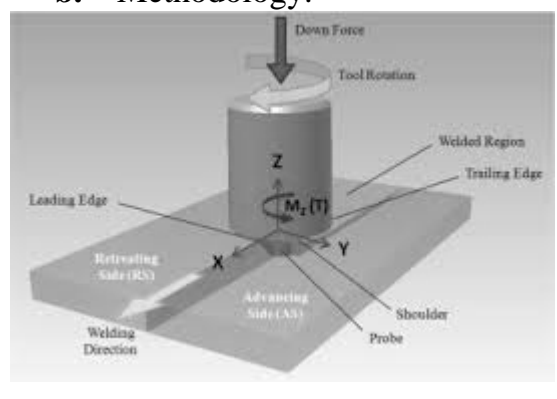

Fig 1: Friction Stir welding

c. Experimental Procedures:

The base metal sheet of $6 \mathrm{~mm}$ thick 6061 (Al-Mg-Si amalgam) and 2024 (Al-Cu composite) Aluminum combinations were welded by butting two plates and blending them together with a pivoting device. Schematic portray of weld joint and device is appeared in Fig. 1. H13 apparatus steel is chosen as instrument material because of its high quality at hoisted temperature, warm weakness resistance and low wear resistance. The measurement of the shoulder and stick utilized were $24 \mathrm{~mm}$, $8 \mathrm{~mm}$ separately and length of the stick is $5.8 \mathrm{~mm}$. A constant axial force is $5 \mathrm{KN}$ applied and tool onward tilt angle of $1.5^{0}$ for all the FSW experiments. Surface morphology of the friction stir weld joints is found to be defect free welds. In view of past work, the trial tests were led with decrease with strung device stick profile with three diverse apparatus turn speeds of 900, 1120 and $1400 \mathrm{rpm}$ and a constant welding speed of $40 \mathrm{~mm} / \mathrm{min}$. By using the Vertical milling machine the experiments are performed (Make HMT FM-2, 10 hp, $3000 \mathrm{rpm}$ ). For various testing samples were cut with required dimensions as per ASTM standards, from the FSP nugget zone by using wire-cut Electrical discharge 
machining (EDM). The schematic diagram of selection of samples for testing is shown in Fig.2. After FSW, micro structural perceptions were done at the cross segment of NZ of weld ments typical to the FSP heading, mechanically cleaned and scratched with Keller's reagent (2 ml HF, $3 \mathrm{ml}$ $\mathrm{HCl}, 20 \mathrm{ml} \mathrm{HNO}_{3}$ and $175 \mathrm{ml} \mathrm{H}_{2} \mathrm{O}$ ) by employing optical microscope (OM). Micro hardness tests were completed at the cross area of NZ of weld ments typical to the FSW heading, tests with a heap of $15 \mathrm{~g}$ and term of $15 \mathrm{sec}$ utilizing a Vickers computerized smaller scale hardness analyzer. The schematic

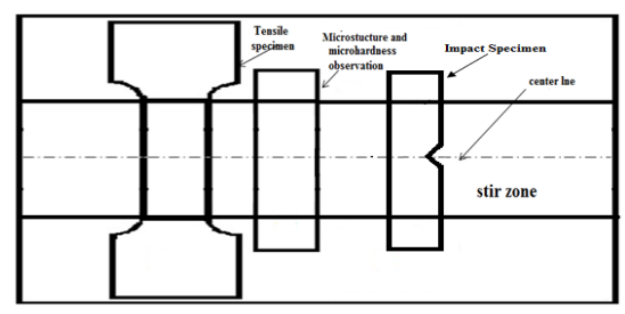

Fig.2 Schematic diagram of weld joint

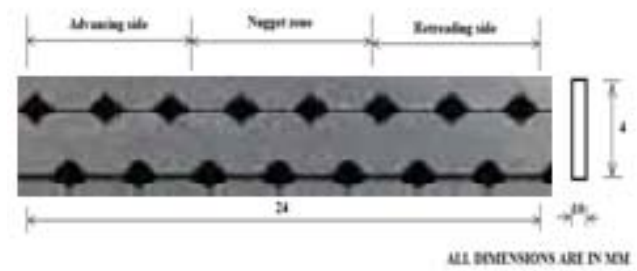

Fig.4.Schematic diagram of micro hardness survey

\section{RESULTS AND DISCUSSIONS:}

\section{a. Microstructure}

The optical microstructure of the diverse zones of the welded dissimilar material is shown in Fig. 2. Though the weld region undergoes a significant amount of thermal cycle, there is a considerable changes occurred in the microstructure of the base metals. On the other hand, the thermal cycle is considerably influenced the Heat affected Zone (HAZ), which is evident from the microstructure Fig 6. However, there is a plastic deformation occurring in this area. In the thermo-mechanically affected zone (TMAZ), there is considerable growth in the grain boundaries which is due to the plastic deformation and the less heat developed during the process. Additionally, it is obvious from the microstructure that a particular grain limit isolates the recrystallized zone (weld chunk) from the disfigured zones of the TMAZ. The dynamically recrystallized zone is the stirred zone, where the material has undergone severe plastic deformation resulting in fine equiaxed grains [9]. The term stirred zone is commonly used in friction stir welding, where sufficient volume of material is stirred. Further from the microstructure of the weld nugget Fig.6, it is evident that the grains are highly refined, which could enhance the strength of the weldment [10]. sketch of micro hardness survey is shown in Fig.3. The tensile specimens were taken from Aluminium compound Friction mix weldments typical to the FSW bearing and made according to ASTM: E8/E8M-011 standards by Wire cut Electrical discharge machining to the required dimensions. The tensile test was conducted with the help of a computer controlled universal testing machine at a cross head speed of $0.5 \mathrm{~mm} / \mathrm{min}$. schematic sketch of microhardness is shown in Fig.4. The Scanning electron microscope (SEM) is also utilized for fractography analysis.

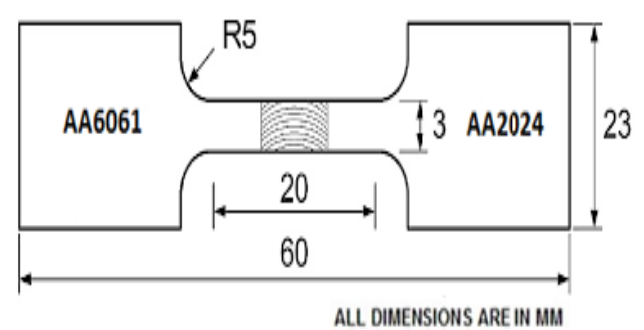

Fig.3 Schematic diagram of selection of samples

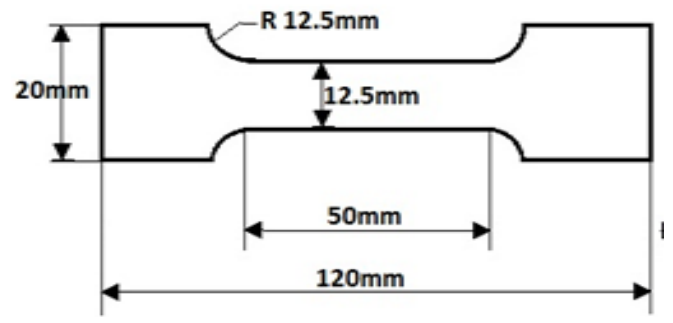

Fig.5. Schematic diagram of selection of samples

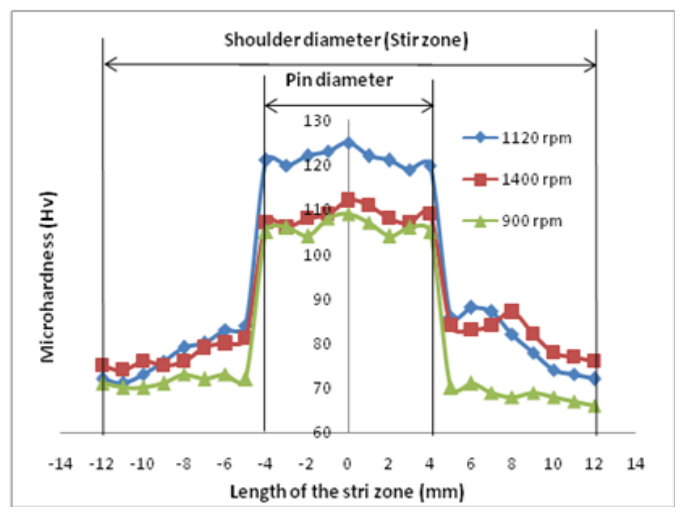

Fig.6. Microstructure of dissimilar joints

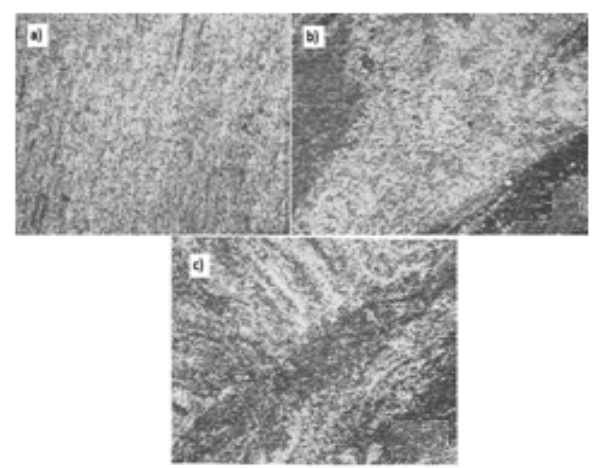


Fig.7. Microhardness survey

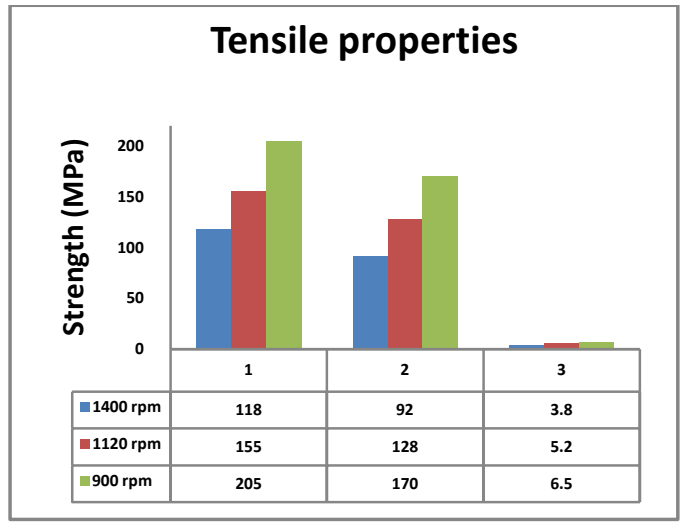

Fig.8. Tensile properties of welded samples

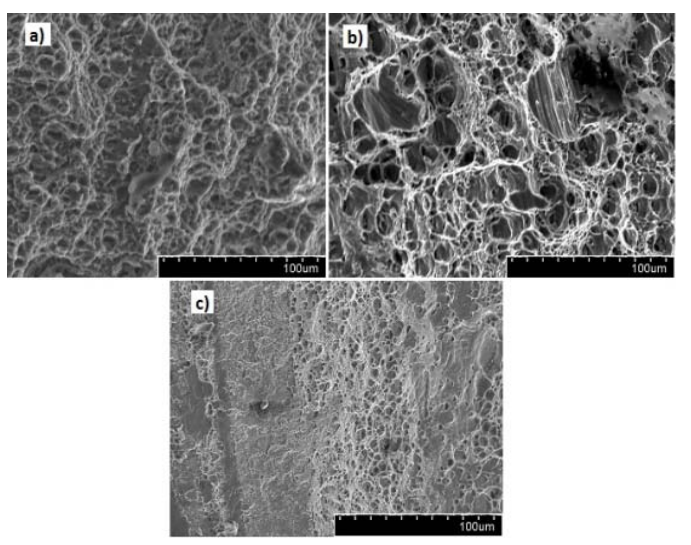

Fig.9. Fracture features of dissimilar joints

\section{b. Microhardness}

The microhardness surveys of different rotational speeds are shown in Fig.7. It is revealed that as the rotational speed increases the microhardness also increases, this is due to the increase in heat input that causes easier and more intense stirring action of the rotating pin resulting in grain refinement which increases the microhardness. There will be a decrease in the microhardness due to the increasing of the rotational speed. Due to the high heat generated that causes matrix softening which will decrease the microhardness. This softening of the NZ is resulted in coarsening and/or dissolution of strengthening precipitates in the Aluminum matrix which occurs especially in heat treatable Aluminum alloys [11].

\section{b. Microhardness}

The microhardness surveys of different rotational speeds are shown in Fig.7. It is revealed that as the rotational speed increases the microhardness also increases, this is due to the increase in heat input that causes easier and more intense stirring action of the rotating pin resulting in grain refinement which increases the microhardness. There will be a decrease in the microhardness due to the increasing of the rotational speed. Due to the high heat generated that causes matrix softening which will decrease the microhardness. This softening of the $\mathrm{NZ}$ is resulted in coarsening and/or dissolution of strengthening precipitates in the Aluminum matrix which occurs especially in heat treatable Aluminum alloys [11].

Table 1. Chemical Composition and mechanical properties of the alloys.
Material Mg Mn Cu Fe $\mathrm{Si}$ Cr $\mathrm{Zn}$ Ti
Al Hardness (HV) \%of Elongation

$\begin{array}{lccccccccccc}\text { AA } 2024 & 1.5 & 0.6 & 4.35 & 0.5 & 0.5 & 0.10 & 0.25 & 0.15 & \text { Remaining } & 19 & 137 \\ \text { AA 6061 } & 1 & 0.15 & 0.27 & 0.7 & 0.6 & 0.19 & 0.6 & 0.15 & \text { Remaining } & 22 & 75\end{array}$

\section{Phase Structures under Scanning electron microscope (SEM)}

An advanced light magnifying lens has a greatest amplification of around 1000x. The settling energy of the magnifying instrument was not just restricted by the number and nature of the focal points additionally by the wavelength of the light utilized for brightening. White mellow has wavelengths from four hundred to seven-hundred nanometres (nm). The regular wavelength is $550 \mathrm{~nm}$ which achieves a speculative purpose of control of commitment (now not perceivability) of the light amplifying focal point in white gentle of around two hundred $-250 \mathrm{~nm}$. The figure underneath indicates two focuses at the breaking points of identification and the two individual spots can even now be recognized. The correct picture demonstrates the two focuses so near one another that the focal spots cover.

\section{X-ray diffraction analysis (XRD)}

$\mathrm{X}$-beam powder diffraction (XRD) is a quick investigative method essentially applied for level recognizable evidence of a crystalline material and can supply facts on unit cell measurements. The tested cloth is finely floor, homogenized, and Normal mass synthesis is resolved. 
Here are the graphs of (XRD) for AA6061 -AA2024 dissimilar metals of aluminum
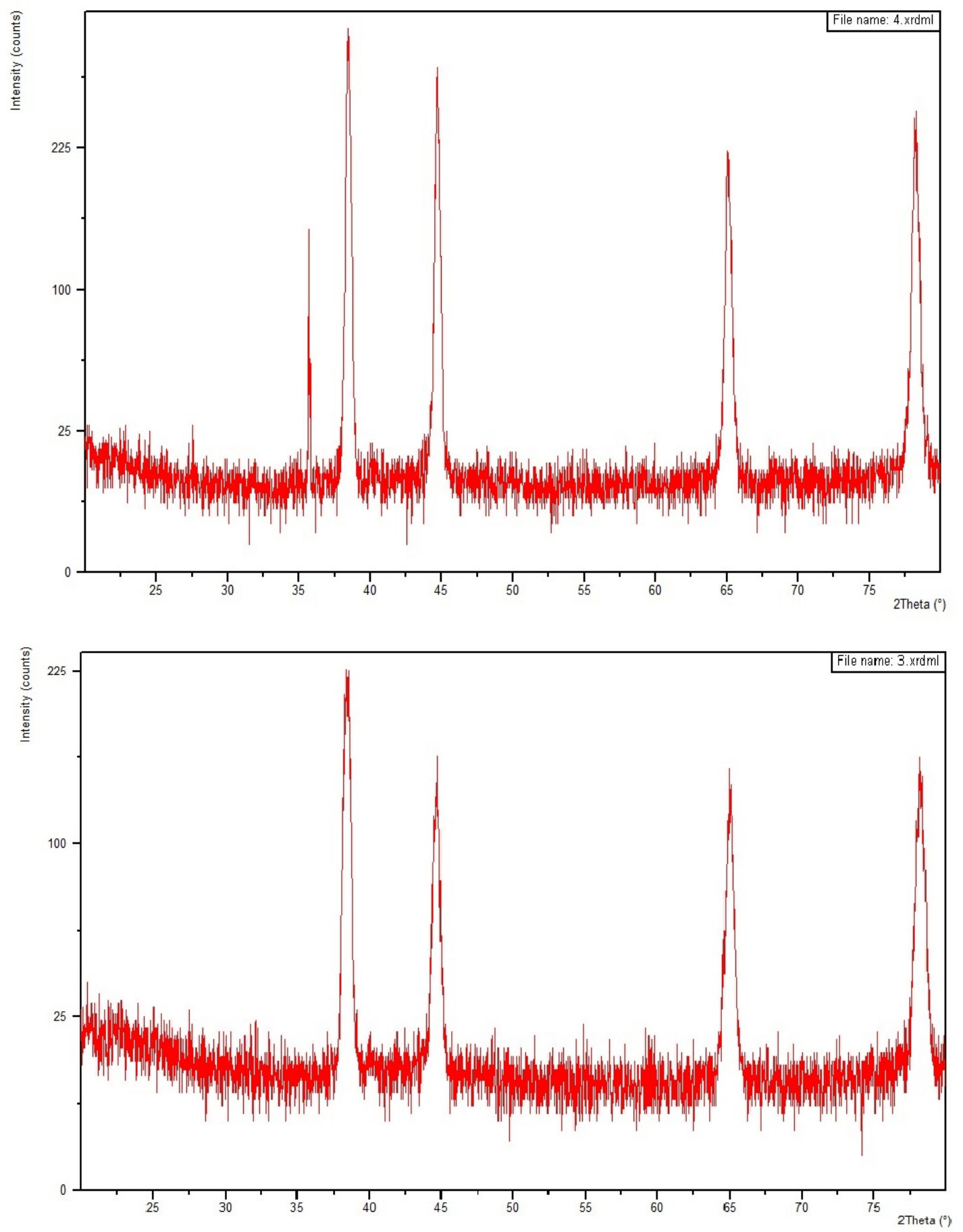

\section{Acknowledgements}

The authors would like to thank the authorities of Research Centre Imarat (RCI) and Defence Metallurgical Research Laboratory (DMRL) for providing the facilities to carry out this work. The authors are also gratified to the Principal and Management of S R Engineering College, Warangal for their continuous shore up throughout this work.

\section{CONCLUSIONS}

In this revision, the effect of tool rotational speed on microstructure and tensile properties of friction stir welded dissimilar aluminum alloys 6061 to 2024 was studied to and following conclusions are made:

- It is marked from the microstructure that a distinct grain boundary separates the recrystallized zone (weld nugget) from the deformed zones of the TMAZ.

- It is revealed that as the rotational speed increases the microhardness also increases due to the increase in heat input that causes easier and more intense stirring action of the rotating pin resulting in grain refinement which increases the microhardness.

- It is revealed that the increasing the rotational speed decreases the UTS, YS and \% EL. 
- $\quad$ The observed tensile properties and hardness are correlated with microstructure and fracture features.

\section{REFERENCES}

[1]. Heidarzadeh, A., Khodaverdizadeh, H., Mahmoudi, A., \& Nazari, E. Tensile behavior of friction stir welded AA 6061-T4 aluminum alloy joints. JOURNAL OF MATERIALS\&DESIGN 2012; 37:166-173.

[2]. Sheikhi, S., \& Bolfarini, C. Preliminary study on the microstructure and mechanical properties of Dissimilar friction stir welds in aircraft aluminium alloys 2024-T351 and 6056-T4 2007; 6:132-142.

[3]. Rao, P. Microstructure and Mechanical Properties of Friction Stir Lap Welded Aluminum Alloy AA2014. Journal of Materials Science \& Technology 2011; 28(5): 414-426.

[4]. Padmanaban, G., \& Balasubramanian, V. Selection of FSW tool pin profile, shoulder diameter and material for joining AZ31B magnesium alloy - An experimental approach. Materials and Design 2009; 30(7): 2647-2656.
[5]. Aruri Devaraju. Influence of Post-weld Rapid cooling on Grain size and Mechanical properties of Friction Stir Welded AA 2014. Materials Today: Proceedings 4 (2017) 3722-3727.

[6]. O. Lorrain, V. Favier, H. Zahrouni and D. Lawrjanice:' Understanding the material flow path of friction stir welding process using unthreaded tool, J. Mater. Process. echnol., 2010, 210,(4), pp 603-609.

[7]. D.H. Choi, B. W. Ahn, C. Y. Lee, Y. M. Yeon, K.U . Song abd S.B. Jung; Effect of pin shapes on joint characteristics of friction stir spot welded AA5132 sheet. Mater. Trans., 2010, 5 , (5), pp.1028- 1032.

[8]. Aruri Devaraju, V Kishan. Preparation of nano surface layer composite (TiB2)p on 6061-T6 Aluminum Alloy via Friction Stir Processing. Materials Today: Proceedings 4 (2017) 40654069.

[9]. Ramesh Babu, S., Senthilkumar, V.S., Madhusudhan Reddy, G., Karunamoorthy, L. Microstructural changes and mechanical properties of friction stir processed extruded AZ31B alloy Procedia Engineering 2012;38:2956 - 2966.

[10]. El-hafez, H. A. Mechanical Properties and Welding Power of Friction Stirred AA2024-T35 Joints 2011; 839-845.

[11]. P Satish Kumar, Ch S R Shastry, Aruri Devaraju. Influence of Tool Revolving on Mechanical Properties 